\title{
Internet addiction among young Bangladeshi adults: critical commentary on Hassan et al. (2020)
}

\author{
Mark D. Griffiths ${ }^{1 *}$ (D) and Mohammed A. Mamun ${ }^{1,2}$
}

\section{Dear Editor,}

We were very interested to read the paper by Hassan et al. [1] examining the prevalence and associated factors of internet addiction (IA) among young Bangladeshi adults. However, there are a number of issues of concern that we would like to raise.

In the first paragraph, Hassan et al. claimed that "Kimberly Young was the first to introduce the concept of internet addiction disorder (IAD) in 1996" (p. 1). The paper that was cited [2] was published in December 1996. However, it was actually Griffiths who published the first paper on internet addiction in November 1996 [3] having already published a more general paper on "technological addictions" in February 1995 [4] as well as populist article on internet addiction in April 1995 [5].

They then cited a paper by Xin et al. [6] to provide worldwide prevalence figures (who simply reported prevalence data from other studies) but did not make any reference to the largest meta-analysis in the IA field by Cheng and $\mathrm{Li}$ [7] who examined prevalence figures comprising 164 studies $(N=89,281)$ from 31 nations in seven world regions, and producing a global estimate of $6 \%$ for IA. Hassan et al. mentioned the wide variations in IA prevalence across different world regions but provided no explanation as to why. Such variation in global IA rates can be due to a number of factors, the most important of which are arguably methodological (e.g., there are many different psychometric instruments used to assess IA, and different researchers use different cutoff points even when the same instrument is being used) [8]. These important factors were not mentioned.

\footnotetext{
* Correspondence: mark.griffiths@ntu.ac.uk

${ }^{1}$ Psychology Department, Nottingham Trent University, 50 Shakespeare Street, Nottingham NG1 4FQ, UK

Full list of author information is available at the end of the article
}

One of the major omissions in the paper is that in their Introduction, not a single previous Bangladeshi study was discussed even though there are many (e.g., [8-21] - see Table 1 for details), and only one was mentioned in the Discussion [10]. Hasan also claimed that: "Most of the studies conducted previously evaluated the prevalence of internet addiction and its predictors in adolescent samples, within the age range of 12 to 18 years" (p. 2). There was no reference for this assertion, and furthermore, it is simply not true. For instance, a systematic review by Kuss et al. [22] of 68 large-scale studies of IA (i.e., studies with over 1000 participants) reported that 24 of the studies had purely adult samples, and a further 15 studies had age ranges that included participants over the age of 18 years. In sum, this systematic review showed that in the large-scale studies in the period they examined, 39 of the 68 studies were not carried out on 12-18-year age group samples.

Another major criticism of Hassan et al.'s study is their scoring on the scale used for IA assessment. The authors said they used the 20-item Bangla version of the Internet Addiction Test (IAT) with a cutoff score of 50 (out of 100) to categorize the participants as internet addicts. However, the Bangla IAT is an 18-item scale (whereas the original English language IAT has 20 items) with total scores ranging from 20 to 90 [15]. The scoring for Bangla IAT is $18-35$ for minimal use, 36-62 for moderate use, and 63-90 for excessive use. However, Hassan et al. did not use the appropriate scoring for the validated Bangla IAT, and given they used a 20 -item scale, it is not even clear if they used the Bangla IAT at all (because there is no 20 -item validated version). Additionally, they cited two papers $[15,23]$ who they claimed had used a cutoff score of 50 to class individuals as internet addicts but neither of these two psychometric studies suggested 50 as a cutoff score. 


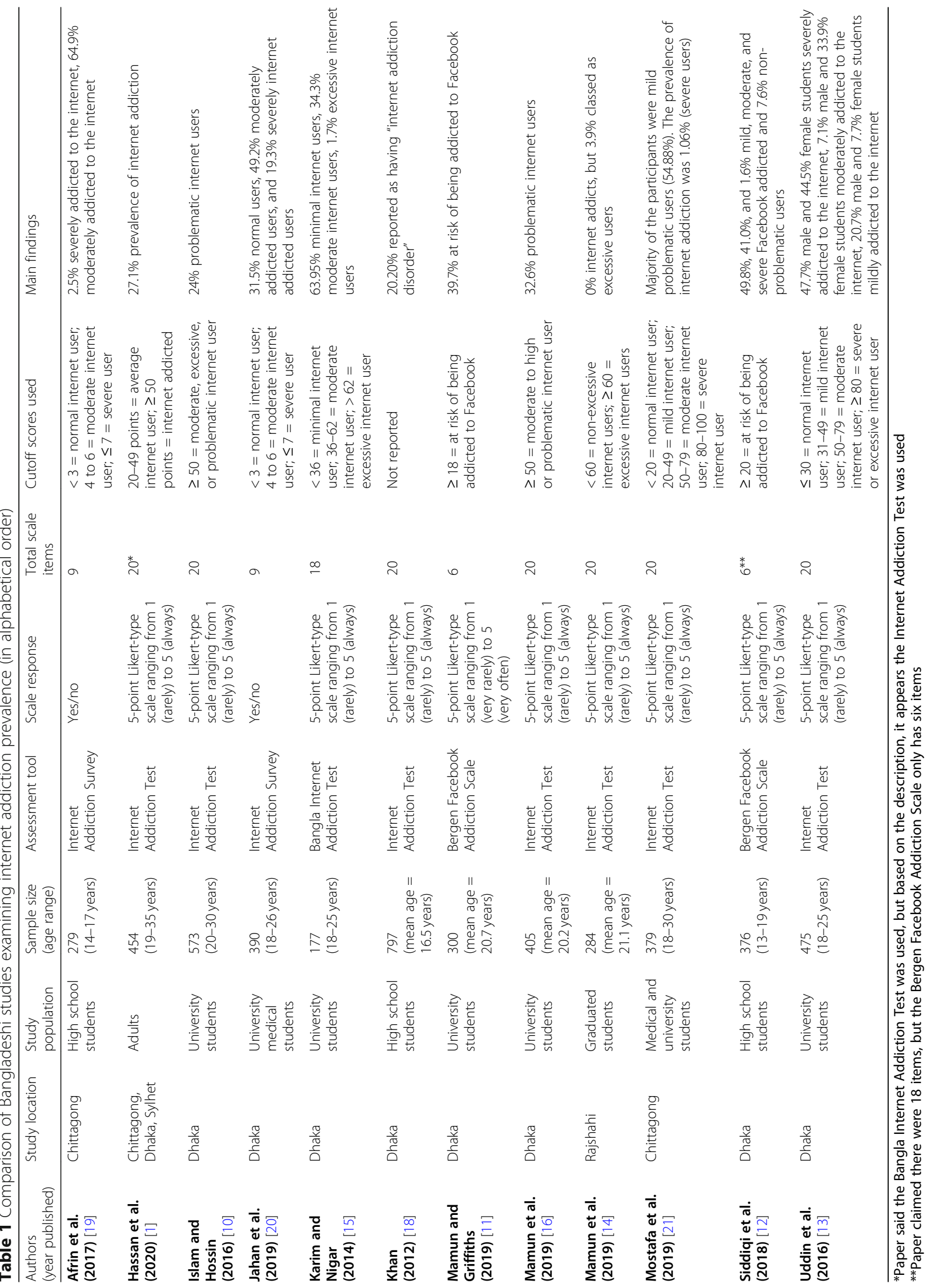


Hassan et al. also wrote that the IAT "has been scientifically analyzed to state an ambiguous psychometric factor structure" (p. 2). On reading this, we were unsure whether the authors deliberately meant to say the factor structure was "ambiguous" (as opposed to "unambiguous") given that they were putting forward the rationale for using the IAT in the first place. However, we would agree that there is no consensus on the psychometric properties of the IAT, because previous studies have reported markedly different factor structures [23-28]. Furthermore, the items for the IAT were developed in 1998 and a number of the items are now very out of date given the rise of smartphones and social media. These are reasons that would weaken the rationale for using the IAT rather than strengthen it.

Hassan et al.'s study reported that over a quarter of their Bangladeshi sample are addicted to the internet (27.1\%). Given a cutoff score of 50 was used to classify individuals as being "addicted" to the internet, it is not surprising the percentage of internet addiction was so high because the vast majority will not have been addicted with such a low cutoff score. There is simply no face validity to the claim that over one quarter of Bangladeshi adults are addicted to the internet. The original developer of the IAT initially suggested a score of above 80 to be classed as an internet addict [29]. Hassan et al. then compared their Bangladeshi prevalence rate to a single previous Bangladeshi study. To our knowledge, at the time of writing, there were at least 14 previous papers specifically examining problematic internet use in Bangladesh (i.e., 10 papers on internet addiction, two on social media addiction, and two commentaries), and of these, 11 papers examined online addiction prevalence in Bangladesh, yet apart from one study [10], none of these was referred to. Hassan et al. then compared their IA prevalence rates to just four other seemingly arbitrary studies in four different countries (i.e., Jordan, Iran, UK, and Taiwan) out of the hundreds that have now been published. The lack of comparison with studies that are clearly relevant (particularly previous Bangladeshi studies) is of concern. Put simply, the "Discussion" did not contextualize the findings in relation to the most relevant studies.

Additionally, Hassan et al. claimed in their conclusion that "[t]he prevalence of excessive internet use is significant among young adults in Bangladesh, which is conforming with the global trend" (p. 7). However, few studies were cited in the paper on which to base such a comparison. Furthermore, "excessive internet use" is not the same as internet addiction given that many excessive internet users are not addicted to the internet (14).

Hassan et al. also provided what they claimed to be study strengths (i.e., sample from various Bangladeshi regions, utilizing a "high number of sociodemographic variables as well as variables related to internet use behavior and regular activity" [p. 6]) without referring to any previous Bangladeshi papers as a benchmark. Confusingly, the authors used a survey to collect the data, but then in the 'Strengths and limitations' section, they said the participants were "conveniently selected for the interview" (p. 6).

Based on these aforementioned criticisms, it can be concluded that the paper by Hassan et al. [1] has many methodological and conceptual weaknesses as well as including a number of assertions that were just simply and factually incorrect.

\section{Abbreviations}

IA: Internet addiction; IAD: Internet addiction disorder; IAT: Internet Addiction Test

\section{Acknowledgements}

None

Authors' contributions

MG wrote the initial draft of the paper based on ideas from MAM. Both authors contributed to subsequent drafts. The author(s) read and approved the final manuscript.

Funding

None

Availability of data and materials

Not applicable

Ethics approval and consent to participate

Not applicable

Consent for publication

Not applicable

\section{Competing interests}

None

\section{Author details}

${ }^{1}$ Psychology Department, Nottingham Trent University, 50 Shakespeare Street, Nottingham NG1 4FQ, UK. ² Undergraduate Research Organization, Savar, Dhaka, Bangladesh.

Received: 16 May 2020 Accepted: 27 August 2020

Published online: 29 September 2020

\section{References}

1. Hassan T, Alam MM, Wahab A, Hawlader MD. Prevalence and associated factors of internet addiction among young adults in Bangladesh. J Egypt Public Health Assoc. 2020;95(1):3.

2. Young KS. Internet addiction: the emergence of a new clinical disorder. CyberPsychology Behav. 1996;1(3):237-44

3. Griffiths MD. Internet addiction: an issue for clinical psychology? Clin Psychol Forum. 1996;97:32-6.

4. Griffiths MD. Technological addictions. Clin Psychol Forum. 1995;76:14-9.

5. Griffiths MD. Netties anonymous: Are some people addicted to the internet? Times Higher Education Supplement; 1995. p. 17.

6. Xin M, Xing J, Pengfei W, Houru L, Mengcheng W, Hong Z. Online activities, prevalence of internet addiction and risk factors related to family and school among adolescents in China. Addict Behav Rep. 2017;7:14-8.

7. Cheng C, Li AYL. Internet addiction prevalence and quality of (real) life: a meta-analysis of 31 nations across seven world regions. Cyberpsychol Behav Soc Netw. 2014;17(12):755-60. 
8. Mamun MA, Griffiths MD. The assessment of internet addiction in Bangladesh: why are prevalence rates so different? Asian J Psychiatr. 2019; 40:46-7.

9. Mamun MA, Griffiths MD. Internet addiction and sleep quality: a response to Jahan et al. Sleep Biol Rhythms. 2019;17(4):463-4.

10. Islam MA, Hossin MZ. Prevalence and risk factors of problematic internet use and the associated psychological distress among graduate students of Bangladesh. Asian J Gambl Issues Public Health. 2016;6:1-11.

11. Mamun MAA, Griffiths MD. The association between Facebook addiction and depression: a pilot survey study among Bangladeshi students. Psychiatry Res. 2019;271:628-33.

12. Siddiqi SA, Islam MZ, Siddiqi KA, Haider MR. Is Facebook addiction leading adolescents to depression? Evidence from Dhaka city, Bangladesh. Value Health. 2018;21:S191.

13. Uddin MS, Mamun A, labal M, Nasrullah M, Asaduzzaman M, Sarwar S, et al. Internet addiction disorder and its pathogenicity to psychological distress and depression among university students: a cross-sectional pilot study in Bangladesh. Psychology. 2016;7:1126-37.

14. Mamun MA, Rafi MA, Al Mamun AS, Hasan MZ, Akter K, Hsan K, et al. Prevalence and psychiatric risk factors of excessive internet use among Northern Bangladeshi job-seeking graduate students: a pilot study. Int J Ment Heal Addict. 2019. https://doi.org/10.1007/s11469-019-00066-5.

15. Karim AKMR, Nigar N. The Internet Addiction Test: assessing its psychometric properties in Bangladeshi culture. Asian J Psychiatr. 2014;10: 75-83.

16. Mamun MA, Hossain MS, Sikder MS, Arafat SMY, Kuss DJ, Griffiths MD. Problematic internet use in Bangladeshi students: the role of sociodemographics, depression, anxiety and stress. 2019. Asian J Psychiatr. 2014; 44:48-54.

17. Shahnaz I, Karim AR. The impact of Internet addiction on life satisfaction and life engagement in young adults. Univ J Psychol. 2014;2:273-84.

18. Khan SA. P-303-Internet addiction disorder among adolescent students. Eur Psychiatr. 2012;27(Suppl 1). Abstracts of the 20th European Congress of Psychiatry.

19. Afrin D, Islam MU, Rabbiand F, Hossain A. The school-level factors associated with internet addiction among adolescents: a cross-sectional study in Bangladesh. J Addic Depend. 2017;3(2):170-4.

20. Jahan SM, Hossain SR, Sayeed UB, Wahab A, Rahman T, Hossain A. Association between internet addiction and sleep quality among students: a cross-sectional study in Bangladesh. Sleep Biol Rhythms. 2019;17(3):323-9.

21. Mostafa A, Hoque R, Chakraborty R, Haque M, Munna MS. Internet use and addiction: a cross-sectional study to ascertain internet utilization level for academic \& non-academic purpose among medical and university students of Bangladesh. Konuralp Tip Dergisi. 2019;11(3):404-15.

22. Kuss DJ, Griffiths MD, Karila L, Billieux J. Internet addiction: a systematic review of epidemiological research for the last decade. Curr Pharm Des. 2014;20:4026-52

23. Widyanto L, McMurran M. The psychometric properties of the Internet Addiction Test. CyberPsychol Behav. 2004;7(4):443-50.

24. Faraci P, Craparo G, Messina R, Severino S. Internet Addiction Test (IAT): which is the best factorial solution? J Med Internet Res. 2013;15(10):e225

25. Ferraro G, Caci B, D'Amico A, Di Blasi M. Internet addiction disorder: an Italian study. CyberPsychol Behav. 2007;10(2):170-5.

26. Khazaal Y, Billieux J, Thorens G, Khan R, Louati Y, Scarlatti E, et al. French validation of the internet addiction test. CyberPsychol Behav. 2008;11(6): 703-6.

27. Watters CA, Keefer CV, Kloosterman PH, Summerfeldt $L$, Parker JDA Examining the structure of the Internet Addiction Test in adolescents: a bifactor approach. Comput Hum Behav. 2013;29(6):2294-302.

28. Hawi NS. Arabic validation of the Internet addiction test. Cyberpsychol Behav Soc Netw. 2013;16(3):200-4

29. Clinical Psychology and Mental Health. Internet Addiction Test. http:// huibee.com/wordpress/wp-content/uploads/2013/11/GLOBALADDICTIONScales-InternetAddictionTest.pdf.

\section{Publisher's Note}

Springer Nature remains neutral with regard to jurisdictional claims in published maps and institutional affiliations.

\section{Submit your manuscript to a SpringerOpen ${ }^{\circ}$ journal and benefit from:}

- Convenient online submission

- Rigorous peer review

- Open access: articles freely available online

High visibility within the field

- Retaining the copyright to your article

Submit your next manuscript at $\boldsymbol{\nabla}$ springeropen.com 